\title{
Generic characterization of electrical test benches for AC- and HVDC-connected wind power plants
}

\author{
Behnam Nouri ${ }^{1}$, Ömer Göksu ${ }^{1}$, Vahan Gevorgian ${ }^{2}$, and Poul Ejnar Sørensen ${ }^{1}$ \\ ${ }^{1}$ Department of DTU Wind Energy, Technical University of Denmark, 4000 Roskilde, Denmark \\ ${ }^{2}$ National Renewable Energy Laboratory, Golden, CO, USA \\ Correspondence: Behnam Nouri (beno@dtu.dk)
}

Received: 19 November 2019 - Discussion started: 9 December 2019

Revised: 28 February 2020 - Accepted: 31 March 2020 - Published: 6 May 2020

\begin{abstract}
The electrical test and assessment of wind turbines go hand in hand with standards and network connection requirements. In this paper, the generic structure of advanced electrical test benches, including grid emulator or controllable grid interface, wind torque emulator, and device under test, is proposed to harmonize state-of-the-art test sites. On the other hand, modern wind turbines are under development towards new features, concerning grid-forming, black-start, and frequency support capabilities as well as harmonic stability and control interaction considerations, to secure the robustness and stability of renewable-energy-based power systems. Therefore, it is necessary to develop new and revised test standards and methodologies to address the new features of wind turbines. This paper proposes a generic test structure within two main groups, including open-loop and closed-loop tests. The open-loop tests include the IEC 61400-21-1 standard tests as well as the additional proposed test options for the new capabilities of wind turbines, which replicate grid connection compliance tests using open-loop references for the grid emulator. In addition, the closed-loop tests evaluate the device under test as part of a virtual wind power plant and perform real-time simulations considering the grid dynamics. The closed-loop tests concern grid connection topologies consisting of AC and HVDC, as well as different electrical characteristics, including impedance, short-circuit ratio, inertia, and background harmonics. The proposed tests can be implemented using available advanced test benches by adjusting their control systems. The characteristics of a real power system can be emulated by a grid emulator coupled with real-time digital simulator systems through a high-bandwidth power-hardware-in-the-loop interface.
\end{abstract}

\section{Introduction}

Wind energy has been one of the most promising renewable energy sources used worldwide, mostly located onshore. In addition, better quality of the wind resource and larger suitable areas in the sea have made offshore installation a considerable choice for wind power plants (WPPs). To date, the total installed capacity has reached $592 \mathrm{GW}$ with a $23 \mathrm{GW}$ share of offshore in 2018 (GWEC, 2018). The new total installations would continue with more than $55 \mathrm{GW}$ each year by 2023 (GWEC, 2018; Wind Europe, 2018).

The increasing installed capacity of variable renewable generation (VRG) has concerned power system operators in terms of stability and reliability of the overall power system.
Consequently, new interconnection requirements, standards, and market mechanisms are evolving in various parts of the world for VRGs, including wind power, to provide various types of essential reliability services to the power systems the role that has been typically reserved for conventional generation (NERC, 2015). Furthermore, the industry has focused on collaboration and harmonization to achieve the technical and economic benefits of a uniform technology and market, especially in Europe (IRENA, 2018; Sørensen et al., 2019). In this way, the European Commission has regulated international requirements for AC- and HVDC-connected powergenerating modules as well as HVDC systems (Commission Regulation 631, 2016; Commission Regulation 1447, 2016). Consequently, updated compliance test standards are 
required to ensure the power quality and stable operation of VRGs, especially WPPs. The development of European network codes and IEC standards are two of best harmonization practices in wind energy.

Compliance test methods are in line with relevant grid connection requirements and standards. Furthermore, wind technology has been matured by research, development, and demonstrations in industrial test sites and laboratories. Figure 1 illustrates the basic compliance test equipment, which had been proposed for low-voltage ride-through (LVRT) capability test in Ausin et al. (2008) and is addressed as an example in IEC 61400-21-1 (2019). Recently, this structure has been adapted for high-voltage ride-through (HVRT) capability tests as well (Langstadtler et al., 2015). In this topology, the voltage divider impedances $\left(X_{\mathrm{sd}}\right.$ and $\left.X_{\mathrm{sc}}\right)$ are used for the LVRT test of the device under test (DUT). Also, the parallel capacitors $\left(C_{\mathrm{L}}\right)$ in series with damping resistors $(\mathrm{Rd})$ are used for the HVRT test. $X_{\mathrm{sl}}$ is used to limit the effect of tests on the utility grid by limiting the current flow from the utility grid during the test. The test apparatus structure shown in Fig. 1 has proven to be a useful tool in the early stages of grid integration research and criticizing of utilityscale wind power. However, it has certain fundamental limitations, such as dependence on a stronger point of interconnections, uncontrollable dynamic change of impedance during testing, and inability to replicate most of $\mathrm{AC}$ grid characteristics (Ausin et al., 2008; Asmine and Langlois, 2017; Gevorgian and Koralewicz, 2016).

Primarily, power quality and transient performance during faults have been essential aspects, which needed to be tested and verified. However, by increasing trends towards $100 \%$ VRG-based grids, the VRGs are required to be developed and featured by advanced capabilities to secure the robustness and reliability of such grids. The operation and stability of VRG-based power systems depend on the interoperability and capabilities of the individual power-generating systems such as wind turbines (WTs). In this way, the state-of-the-art WTs are under development towards advanced features, especially grid-forming and black-start capabilities. These new capabilities necessitate appropriate test and assessment standards in the near future (Langstadtler et al., 2015; Asmine and Langlois, 2017; Gevorgian and Koralewicz, 2016). In addition, by increasing wind power installations, it is required to study the rising challenges such as harmonic resonances and control interactions of WPPs in connection to different types of AC and HVDC transmission systems according to Hertem et al. (2016), Zeni et al. (2016), and Buchhagen et al. (2015). Thus, it is essential to adapt or define new regulations, standards, and compliance test methods to analyse the developments and issues regarding wind energy. To date, several standards and recommendations such as IEC, IEEE, DNV GL, and CIGRE have been published for design, simulation, operation, and testing of electrical aspects of WTs (IEC 61400-21-1, 2019; IEEE Std. 1094, 1991; DNVGLST-0076, 2015; CIGRE Technical Brochure 766, 2019). The
IEC standards as the leading international standards for the test and assessment of wind turbines have been reviewed in this paper.

In this paper, the authors aim to extend the state-of-the-art developments in wind energy towards harmonized test methods and propose additional test options to the standard tests to extend the applications of advanced industrial test benches regarding operation and stability assessment of WTs as well as WPPs. In Sect. 2, grid connection compliance tests, including typical grid connection topologies, IEC standards, and electrical test levels, have been introduced. Section 3 describes the state-of-the-art industrial test benches and illustrates the generic structure of converter-based test equipment. In Sect. 4, the electrical characteristics of different grids to be emulated in a test site have been studied and proposed. Finally, Sect. 5 proposes the generic structure of test options consisting of the recommended tests in IEC standards as well as proposed additional test options for open-loop tests as well as closed-loop tests for WTs and WPPs.

\section{Grid connection compliance tests}

The wind power can be transmitted through either $\mathrm{AC}$ or HVDC transmission systems to the main AC grids. In addition, there is an increasing trend to develop WPPs in offshore areas because of the higher power capacity of offshore winds and limited onshore sites (Wind Europe, 2018; Cutululis, 2018; Kalair at al., 2016). According to the European Wind Energy Association (EWEA) (Pierri et al., 2017), potentially, European offshore wind power can supply 7 times Europe's demand. Figure 2 illustrates a typical structure for AC and HVDC connections of offshore WPPs. As shown in Fig. 2a, the AC-connected offshore WPP connects to the main onshore grid through high-voltage submarine cables and transformers. In addition, the shunt inductors are required to dampen the possible over-voltage phenomena caused by the capacitive effect of the AC cables. The typical structure of an HVDC-connected offshore WPP is illustrated in Fig. 2b, which consists of HVDC transmission cables, transformers, AC-DC converters, and harmonic filters of the converters. An HVDC connection has economic advantages for long distances, especially in the case of offshore WPPs (Hertem et al., 2016; Cutululis, 2018; Kalair at al., 2016). Hence, the recent interest in wind energy has been focused on offshore WPPs, and HVDC systems are required due to long distances from the main AC grids. The collector system voltages in AC- and HVDC-connected WPPs (i.e. medium-voltage (MV) buses in Fig. 2) are typically 33 and $34.5 \mathrm{kV}$ in Europe and the US, respectively. Recently, several $66 \mathrm{kV}$ collector systems in offshore WPPs have been demonstrated. Therefore, $66 \mathrm{kV}$ seems to be a general trend in collector system design in the offshore wind industry (Wiser et al., 2018). 


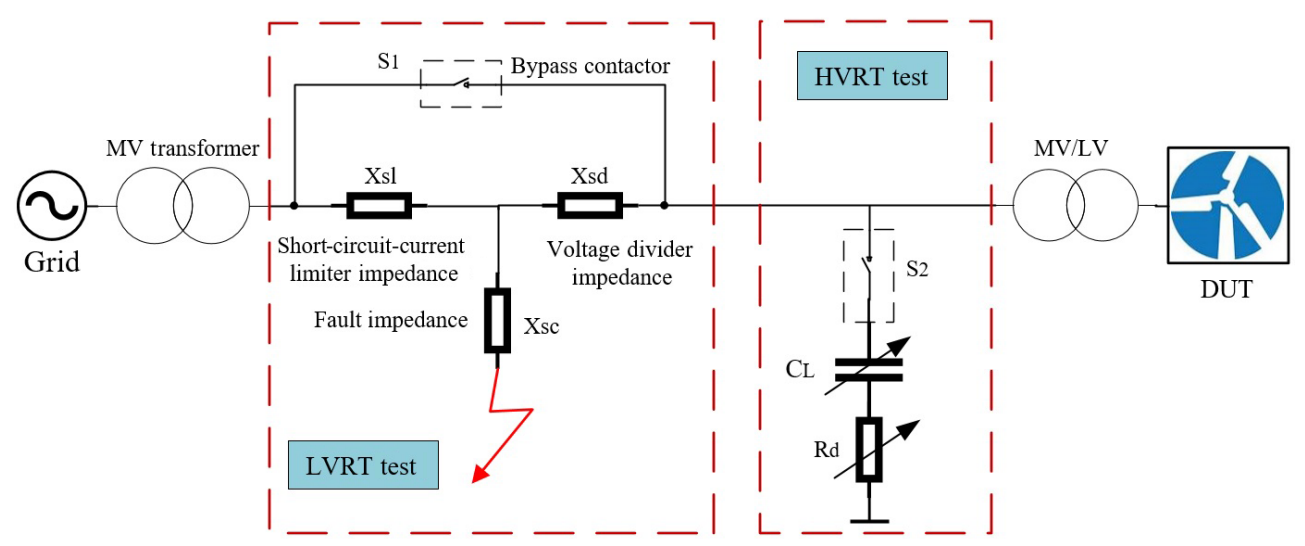

Figure 1. The basic structure of impedance-based topology for LVRT and HVRT capability tests (Ausin et al., 2008; Langstadtler et al., 2015).
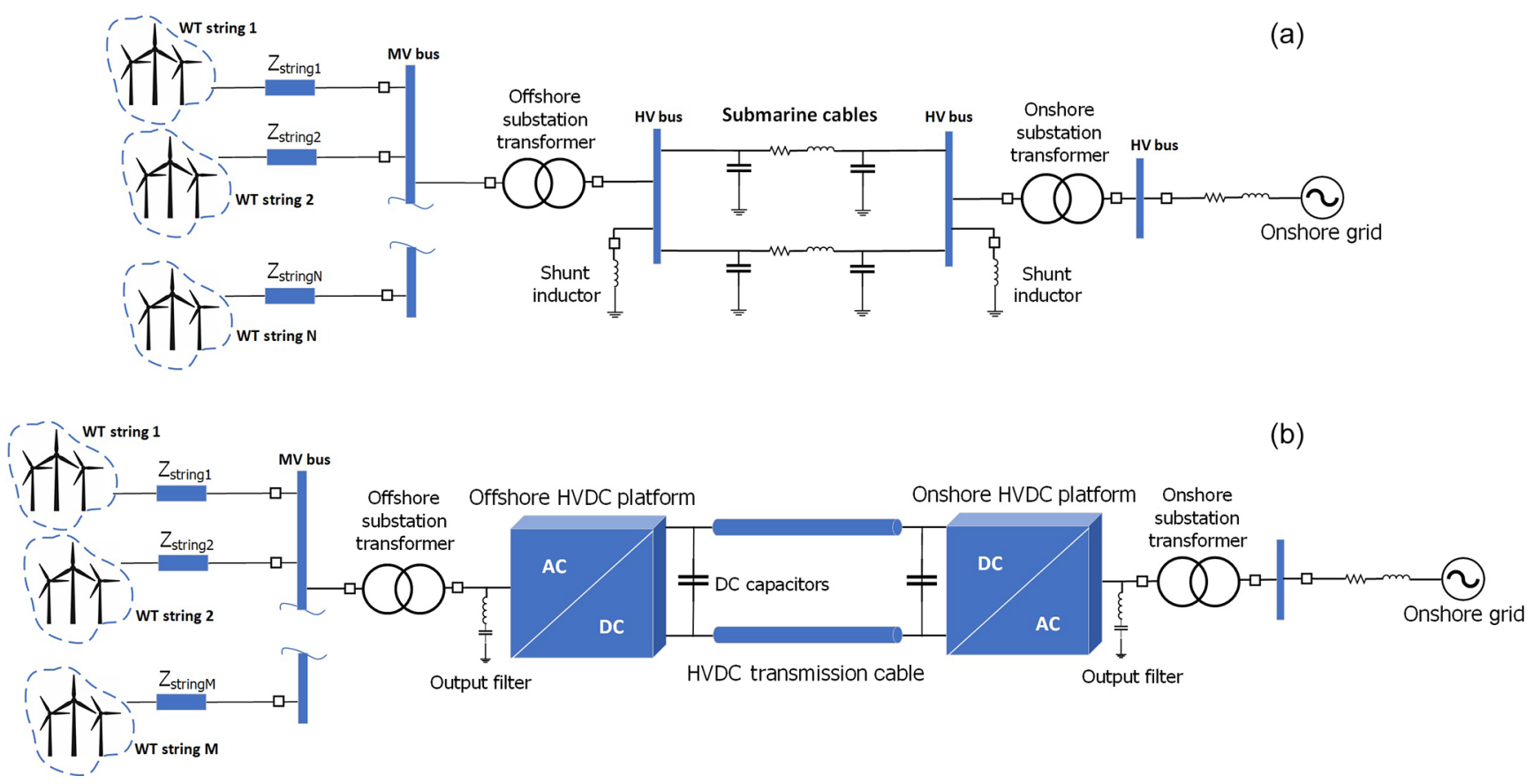

Figure 2. Typical structure of AC-connected (a) and HVDC-connected (b) offshore WPPs (Cutululis, 2018; Kalair at al., 2016).

In European network codes, the requirements have been regulated for AC-connected offshore and onshore as well as HVDC-connected power-generating modules (PGMs) (Commission Regulation 631, 2016; Commission Regulation 1447, 2016). According to Nouri et al. (2019), the requirements for AC-connected offshore and onshore PGMs are mostly similar, while relatively different operation ranges and conditions have been considered for AC- and HVDCconnected PGMs. The AC and HVDC transmission systems impose different electrical characteristics on WPPs. Consequently, different control schemes and design considerations have been applied for WTs and WPPs. Network code compliance tests and standards are critical factors in preserving the reliability and stability of WPPs. Thus, in the next part, IEC standards, as the leading international standards for test and assessment of wind turbine capabilities, have been reviewed.

\subsection{IEC standards for assessment of wind energy}

In 1988, Technical Committee 88 (TC88) of the IEC began its efforts to organize international standards for wind turbines as 61400 series. TC88 consists of several working groups, projects, and maintenance teams to develop and issue standards, technical reports, and specifications (Andresen et al., 2019). 


\subsubsection{IEC standards for electrical tests}

Initially, TC88 focused on power performance (i.e. power curve) tests and structural and mechanical design. The works on electrical tests started in 1997 as IEC 61400-21 series by the working group WG21.

The second edition of IEC 61400-21 was published in 2008 to cover the definition and specifications for measurement and assessment of power quality characteristics for wind turbines. Currently, IEC TC88 WG21 is working on four new documents for the IEC 61400-21 series, where the title is changed from power quality characteristics to electrical characteristics appreciating that not only power quality characteristics are included (Andresen et al., 2019). To date, there is no IEC standard for testing the electrical characteristics of WPPs, but only for testing single WTs. Regarding the grid connection compliance assessment, the evaluation of performance and quality of WPPs is based on measurements, simulations, and model validation tests (Ausin et al., 2008; Asmine and Langlois, 2017; Andresen et al., 2019).

Recently, IEC 61400-21-1 has been published and replaced the second edition of 61400-21. IEC 61400-21-1 specifies test methods for electrical characteristics of wind turbines (IEC 61400-21-1, 2019). Also, IEC 61400-21-2 specifies test methods for electrical characteristics of WPPs (Andresen et al., 2019). Concerning the growing issues regarding harmonics in WPPs, IEC 61400-21-3 aims to focus on harmonic modelling as a technical report. IEC TR 6140021-3 provides a starting point for the required frequencydomain modelling of wind turbines (IEC TR 61400-21-3, 2019). Furthermore, IEC 61400-21-4 recommends a technical specification for component and subsystem tests (Andresen et al., 2019). IEC 61400-21-1 and IEC 61400-21-3 were published in 2019, while 61400-21-2 and 61400-21-4 may be published in 2021.

In addition, the IEC 61400-27 series specifies standard dynamic electrical simulation models for wind power generation. The first edition of IEC 61400-27-1, published in 2015, specifies generic models and validation procedures for wind turbine models. Furthermore, the next edition is under development to expand the scope towards WPP models in addition to the WT models (Sørensen, 2019). The next edition consists of two parts: IEC 61400-27-1 specifying generic models for both WTs and WPPs and 61400-27-2 specifying validation procedures.

\subsubsection{Electrical test levels}

According to the IEC-61400-21-1 (IEC 61400-21-1, 2019), the electrical characteristics to be simulated and validated for wind turbines consist of five different categories: power quality aspects, steady-state operation, control performance, transient performance or fault ride-through capability, and grid protection. The electrical characteristics of WTs can be measured and tested at different levels. The test levels consist of component test level (such as capacitors and switches), subsystem test level (such as nacelle and converter), field measurement at wind turbine level (or type test), and field test or measurement at WPP level (IEC 61400-21-1, 2019). Furthermore, the WT level tests can be split into two subcategories: (a) testing of the full drivetrain connected to a low-voltage test bench and (b) testing of the full drivetrain connected to a medium-voltage test bench via the WT's transformer with a full set of protection and switchgear (Koralewicz et al., 2017). The second option is closer to reality since it includes impacts of transformer impedance and configuration and protection settings on transient performance. In IEC 61400-21-1 (2019), an overview of the required and optional test levels for different test and measurement requirements is provided.

Today, to have a flexible and economical solution for grid connection compliance tests and model validations, the trend is to perform tests at lower levels, such as WT and subsystem levels. The test results concern wind farm developers and system operators in terms of WPP model validation and grid connection compliance and WT manufacturers in terms of WT design and simulation model validations. This way, the results of tests are considered to be transferable and useful for the assessment of WTs as well as WPPs and developed simulation models (Ausin et al., 2008; Zeni et al., 2016; Koralewicz et al., 2017). However, in some cases performing field tests and measurements is still necessary as reported in Asmine and Langlois (2017). Accordingly, the Hydro-Québec TransÉnergie experience (Asmine and Langlois, 2017) regarding the inertial response has shown that an adequate evaluation of the inertial response cannot be performed accurately at WT level and should include evaluations at the WPP level. As another example, the power quality assessment of WPPs is either assessed using scaling rules of WT test results or accomplished by the assessment of online measurement data. The online monitoring is achieved during the first year of operation of the WPP (Asmine and Langlois, 2017). However, the increasing challenges, such as harmonic resonances, grid interactions, and voltage and frequency stability issues, have proven the need for more extended analysis and assessment of WPPs. In this regard, the generic converter-based test bench and possible test and assessment solutions for WTs and WPPs are proposed in the next parts of this paper.

\section{Generic converter-based test bench}

Different electrical test benches as controllable grid interfaces (CGIs) have been reported for grid dynamics emulation in Ausin et al. (2008), Gevorgian and Koralewicz (2016), Espinoza and Carlson (2019), Espinoza et al. (2015), and Yang et al. (2012). The impedance-based test equipment in Fig. 1 is only intended for the fault ride-through capability tests. A more advanced and flexible topology is a full-power converter-based CGI, which is shown in Fig. 3. This topol- 
ogy has been used in the latest industrial test benches and is studied in the next parts of this paper.

In MEGAVIND (2016), a mapping of global test and demonstration facilities serving the wind industry in Europe and the US is presented by topic and location. Accordingly, most of the latest industrial test benches are based on power electronic converters. Converter-based test equipment provides emulation of unlimited test scenarios applicable to power systems of various sizes (sizable interconnected power grids, island systems, or mini-grids) operating at both 50 and $60 \mathrm{~Hz}$, with full controllability over electrical characteristics of emulated grids. The generic schematic diagram of a converter-based test rig is illustrated in Fig. 3. Generally, a converter-based test bench consists of three main parts: device under test (DUT), wind torque emulator, and grid emulator or CGI. In Fig. 3, the DUT is a WT nacelle. The CGI can also be used for testing of complete WTs, in which case the wind torque emulator in Fig. 3 is not required.

In Table 1, the specifications for some remarkable advanced test sites are illustrated. As it is presented in Fig. 3, the application of multilevel drive converter modules in parallel connections is a typical topology to establish a mediumpower and medium-voltage source as grid and wind torque emulators (Averous et al., 2017; Gevorgian, 2018; Jersch, 2018; Rasmussen, 2015; Tuten et al., 2016). The multilevel converters, such as three-level neutral point clamped (3LNPC) and H-bridge topologies, are developed to achieve higher efficiency and lower harmonic distortion rather than conventional two-level converters, and they reduce the size of harmonic filtering and undesired interference.

According to the Table 1, a group of test sites such as available test setups in NREL (National Renewable Energy Laboratory, USA), Fraunhofer IWES (Fraunhofer Institute for Wind Energy Systems, Germany), and CENER (National Renewable Energy Centre, Spain) have used three-level NPC drive converters developed by the ABB company. The ABB drive converters are controlled by the direct torque control (DTC) method with integrated gate-commutated thyristor (IGCT) switches (ABB, 2018). On the other hand, in the second group, with LORC (Lindø Offshore Renewables Center, Denmark) and Aachen (RWTH Aachen University, Germany), the converters are three-level NPCs developed by the GE company (General Electric). GE's medium-power drive converters are controlled by advanced vector control (AVC) using insulated gate bipolar transistor (IGBT) switches (GE, 2018). In addition, different types of converters would be utilized in a test site. For instance, the drivetrain test facility at Clemson University was established using multilevel H-bridge drive converters developed by the TECOWestinghouse company (Tuten et al., 2016). Each converter developer utilizes different components, control methods, and interface algorithms. However, all of the test benches should be able to perform tests according to the standards and research objectives, and minimize the effect of non-ideal emulation of a real test environment for the DUT. In most of the test sites, a real-time digital simulation (RTDS) system is used to get to a dynamic online model of the grid as well as the overall system.

The main limitation of converter topology shown in Fig. 3, as well as any converter-based test rigs, is limited overcurrent capability. This constraint can be addressed by oversizing the MVA rating of the test side converter similar to what was done in NREL's CGI (7 MVA continuous power rating but capable of operating at 40 MVA short-circuit capacity for $2 \mathrm{~s}$; Gevorgian, 2018) as given in Table 1. Oversizing of converters for this purpose is costly but is necessary for LVRT testing of doubly fed induction generator (DFIG) WTs, which can produce higher levels of short-circuit current contribution. In this regard, high-power and short-circuit capacity are achieved by parallel connection of converters in each converter unit as indicated by $\mathrm{N}(\mathrm{ARU})$ and $\mathrm{M}(\mathrm{AGE})$ in Table 1.

Furthermore, the majority of companies have plans to develop their sites as such to be able to test a wide range of WTs, including medium-power to higher-power ratings, which are mostly for offshore applications. According to Pietilaeinen (2018), the new trends in the development of grid simulators are as follows:

- higher-power ratings, up to $24 \mathrm{MW}$ rating and $80 \mathrm{MVA}$ short-circuit power;

- grid impedance emulation, virtual impedance emulation using the converters' control system;

- higher bandwidth for harmonic injections, up to 25 th or even 100th harmonic injection for harmonic stability tests;

- extension of use for component and subsystem tests, and mobility of test equipment to perform field tests.

The three main parts of the generic converter-based test rig, which is shown in Fig. 3, are introduced as follows.

\subsection{Device under test}

The device under test (DUT) can be one or more of a whole WT or its subsystems such as a nacelle consisting of converters and a generator, or only converters of a WT. Today, WTs are mainly full-converter or DFIG types in new developed WPPs. The main objective of test facilities is to perform compliance electrical and mechanical tests in the WT and subsystem test levels on the DUT.

\subsection{Grid emulator}

The grid emulator or CGI consists of two back-to-back converter units to emulate real grid characteristics for the DUT, as is shown in Fig. 3. The first converter unit is connected to the utility grid through a transformer, which is called the 


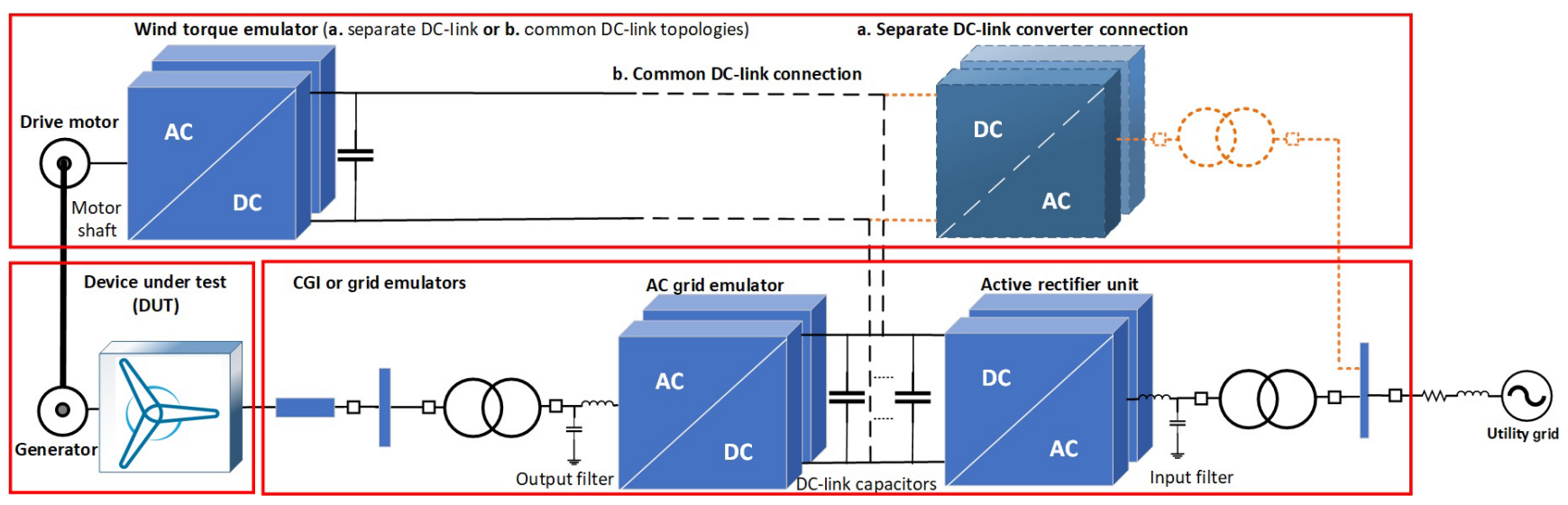

Figure 3. Proposed generic schematic diagram of a converter-based test bench.

Table 1. Comparison of different concepts applied in industrial test benches.

\begin{tabular}{|c|c|c|c|c|c|c|c|c|}
\hline $\begin{array}{l}\text { Test } \\
\text { centre }\end{array}$ & $\begin{array}{l}\text { CGI } \\
\text { rating }\end{array}$ & $\begin{array}{l}\text { Short-circuit } \\
\text { capacity }\end{array}$ & $\begin{array}{l}\text { Torque emulator } \\
\text { rating }\end{array}$ & Converter type & $\mathrm{N}(\mathrm{ARU})^{\mathrm{a}}$ & $\mathrm{M}(\mathrm{AGE})^{\mathrm{b}}$ & $\begin{array}{l}\text { Converter } \\
\text { control }\end{array}$ & RTDS \\
\hline LORC & $15 \mathrm{MVA}$ & 30 MVA & $13 \mathrm{MW}$ & 3L-NPC GE (IGBT) & 2 & 2 & AVC & no \\
\hline Aachen & $3.5 \mathrm{MVA}$ & $7.5 \mathrm{MVA}$ & $4 \mathrm{MW}$ & 3L-NPC GE (IGBT) & 1 & 1 & AVC & yes \\
\hline NREL & 7 MVA & $40 \mathrm{MVA}$ & $5 \mathrm{MW}$ & 3L-NPC ABB (IGCT) & 1 & 4 & DTC & yes \\
\hline F. IWES & 15 MVA & 44 MVA & $10 \mathrm{MW}$ & 3L-NPC ABB (IGCT) & 2 & 3 & DTC & yes \\
\hline CENER & 9 MVA & $18 \mathrm{MVA}$ & $9 \mathrm{MW}$ & 3L-NPC ABB (IGCT) & 1 & 2 & DTC & yes \\
\hline Clemson & 15 MVA & $20 \mathrm{MVA}$ & 7.5 and $15 \mathrm{MW}$ & H-bridges TECO-W & 2 & 2 & AVC & yes \\
\hline
\end{tabular}

a N(ARU): number of ARU modules. ${ }^{b}$ M(AGE): number of AC grid emulator modules.

"active rectifier unit (ARU)". Generally, the control objective for the ARU is to regulate the DC-link voltage in a reference value within an acceptable deviation range. The reference value for DC link depends on the type and objectives of the test. Thus, the ARU should perform as a current source to exchange active and reactive power between the DC-link capacitors and the utility grid.

The second converter unit is connected to the DUT through a transformer, which is called the "AC grid emulator". The controller of the AC grid emulator is designed to emulate a realistic grid dynamic and steady-state behaviours. In addition, to have an acceptable range of total harmonic distortion and to prevent unwanted harmonics and noise interference in the setup, appropriate passive filters on both sides of the converters have been considered. Also, in some cases, active filtering methods are implemented by additional control strategies such as selective harmonic elimination and interleaved harmonic elimination methods, to decrease the need for the large passive filters (Gevorgian and Koralewicz, 2016; Averous et al., 2017). Thus, by this structure, the power flow in the CGI is controlled. Meanwhile, the assessment of DUT behaviour would be accomplished by online simulations, measurements, and data analysis.

\subsection{Wind torque emulator}

Assessment of electromechanical interactions of WTs can be achieved by using the wind torque emulator part in the test bench. As is illustrated in Fig. 3, the wind torque emulator would either be connected directly to the DC link of CGI as a common DC link, or have a separate ARU unit connected to the utility grid. A separate DC link for the wind torque emulator enables an independent control system and reduces the side effects of power electronic converters on each other such as harmonic interference, DC-link voltage deviations, and control interactions.

The wind torque emulator is a prime mover system consisting of a drive converter connected to an AC or DC motor. This way, the characteristics of the missing WT rotor in the laboratory environment would be recreated. This objective is necessary for hardware-in-the-loop (HiL) testing of DUTs, especially for the tests, such as the LVRT capability test, in which a realistic emulation of rotor torque for the DUT's main shaft is required. This requirement implies an accurate emulation of steady-state and dynamic torque characteristics of the rotor, including the rotor inertia and its eigenfrequencies, as studied in Neshati et al. (2016).

The drive system converts the electrical power to the mechanical power for the shaft of the generators. On the other 
hand, the generators convert the mechanical power to the electrical power in connection to the CGI. In this way, the power flow circulates through the utility grid, wind torque emulator, and grid emulator. The first constraint of this power circulation is the manageable power loss. In addition, the second constraint is required maximum power flow during the LVRT capability test. During voltage sag emulation by the AC grid emulator, the ARU has to provide the active power to the wind power emulator. Thus, the maximum required power flow and power losses during tests should be considered in design of converter units and their cooling system.

\section{Test bench characteristics}

The advanced specification of converter-based test equipment facilitates performing grid connection compliance tests and gives the opportunity to analyse, predict, and eliminate the possible challenges facing wind energy technology. In this part, electrical characteristics of an emulated AC grid by a converter-based test site have been studied.

\subsection{Emulated grid characteristics}

The characteristics of a real power system that test article is exposed to at its point of common coupling (PCC) can be emulated by CGI coupled with RTDS through a powerhardware-in-the-loop (PHiL) interface. The AC grid emulation can provide flexible options regarding the electrical characteristics of power grids, including impedance, short-circuit ratio, inertia, and background noise.

\subsubsection{Grid impedance}

One of the main differences between AC and HVDC connections is the structure of equivalent grid impedance as shown in Fig. 2. Especially in AC-connected offshore WPPs with long AC export submarine cables, the grid impedance is high and frequency-dependent, which can create resonances and instability (Kocewiak et al., 2013). In addition, in the case of onshore AC connections, the main issue would be considerably high grid impedance for long-distance WPPs. Typically, for AC offshore connections, the grid impedance would be considered capacitive, while for AC onshore connections it would be high inductive impedance. In addition, regarding HVDC-connected offshore WPPs, the equivalent resistance of the grid impedance is low. Thus, the natural resonance damping capability in such grids is low, and the converters of WTs are prone to interact with the converters of the HVDC system. Therefore, the harmonic stability of an HVDC connection is very vulnerable. The interactions among grid impedance, converter controllers, and passive filters can cause instability and resonance issues in a WPP as well as HVDC station (Buchhagen et al., 2015; Kocewiak et al., 2013; Sowa et al., 2019; Beza and Bongiorno, 2019).
In a synchronous-generator-based grid, large electrical loads facilitate the grid stability during dynamics and resonances. However, in such grids, the sub-synchronous control interactions between WTs and transmission lines in series with voltage compensation capacitors, which is investigated in Chernet et al. (2019), are still a serious concern. The impedance of the test bench can be arranged as such to study the sub-synchronous control interaction as well. Therefore, it is essential to consider the emulation of grid impedance characteristics in the test environment and test results. The controllable dynamic impedance emulation is another advantage of a converter-based grid emulator (in comparison to the voltage divider test equipment shown in Fig. 1), which imposes fewer uncertainties regarding equivalent impedance to the point of connection of the DUT.

\subsubsection{Short-circuit ratio}

As the AC system impedance increases, the voltage magnitude of the AC system becomes even more sensitive to the power variations at the PCC. This dependency is usually determined by the short-circuit ratio (SCR), which is a ratio of the short-circuit capacity $\left(S_{\mathrm{sc}}\right)$ versus the rated power of the AC grid at PCC $\left(P_{\text {npcc }}\right)$ as illustrated in Eqs. (1) and (2) (IEEE Std. 1204, 1997).

$S_{\mathrm{sc}}=\frac{V_{\mathrm{pcc}}^{2}}{Z_{\text {grid }}}$

Here $Z_{\text {grid }}$ is the equivalent impedance of the grid, and $V_{\mathrm{pcc}}$ is the nominal phase-to-phase voltage at PCC.

$\mathrm{SCR}=\frac{S_{\mathrm{sc}}}{P_{\mathrm{npcc}}}$

The investigations in Fan and Miao (2018) have shown that a weak grid interconnection of an AC-connected WPP (e. g., ERCOT, USA) can lead to poorly damped or undamped voltage oscillations. The SCR evaluation for an HVDCconnected AC grid is defined as an effective short-circuit ratio (ESCR). ESCR is the ratio of the short-circuit power of the AC grid along with HVDC converter filters and capacitor banks $\left(S_{(\mathrm{AC}+\mathrm{HVDC})}\right)$ to the rated power of the HVDC link $\left(P_{\mathrm{HVDC}}\right)$, as presented in Eq. (3). Typical weak HVDC connections have an ESCR less than 2.5 (Yogarathinam et al., 2017).

$\mathrm{ESCR}=\frac{S_{(\mathrm{AC}+\mathrm{HVDC})}}{P_{\mathrm{HVDC}}}$

The studies in Zhou et al. (2014) have concluded that the operation of the HVDC converter is greatly affected by the angle of the $\mathrm{AC}$ grid impedance, converter phase-locked loop (PLL) parameters, and AC system strength. A converterbased test bench has a similar structure to an HVDC connection system with two back-to-back converters. Thus it can be used to emulate an HVDC system with different ESCRs 
for the DUT. These emulations would be implemented by adjusting the control system, modular selection of the CGI converters, and reconfiguration of output filter components, especially in a test setup consisting of an RTDS system.

\subsubsection{Grid inertia}

The grid inertia is another important criterion for evaluation of grid strength. The effective inertia constant $\left(H_{\mathrm{dc}}\right)$ for an HVDC-connected AC grid is defined as the ratio of the total rotational inertia of the AC system $\left(E_{\mathrm{TI}}\right)$ in megawattseconds to the MW rating of the HVDC link, which is illustrated in Eq. (4).

$H_{\mathrm{dc}}=\frac{E_{\mathrm{TI}}}{P_{\mathrm{HVDC}}}$

$H_{\mathrm{dc}}$ is less than 2.0 for weak grids (Yogarathinam et al., 2017). In an HVDC-connected offshore WPP, there is no rotating mass. Therefore the inertia is zero. A test bench converter can be considered as an HVDC system connection for the DUT. In this way, by adjusting the CGI control system, it is possible to emulate different inertia ranges to evaluate the control performance of WTs.

\subsubsection{Background harmonics}

The background noise and harmonics are high-frequency content in the grid voltage as part of harmonic sources. By increasing converter-based installations, the harmonic injection and interactions have concerned the power system operators and WPP developers. The possible harmonic challenges can be studied in two main categories: harmonic emission sources and harmonic stability issues.

Harmonic emission sources refer to non-ideal power sources and non-linear loads that generate harmonics. The harmonic emission is a power quality issue and would be assessed by measurement data analysis (Sørensen et al., 2007). The assessment of emission limits for the connection of distorting installations at medium- and higher-voltage levels is recommended in the IEC 61000-3-6 technical report. The emission limits depend upon the consented power of the connected power plant and the system characteristics (Joseph et al., 2012).

In addition, harmonic stability issues are significant in the case of fully renewable-based power grids since converters mostly dominate such grids. Therefore, HVDC-connected offshore WPPs are the main subject of harmonics and resonance studies. As an example, BorWin1 is the first offshore HVDC station and is developed to transmit wind energy from BARD offshore WPP to the onshore grid in Germany (Buchhagen et al., 2015). So far several serious problems such as outages of the HVDC station, severe harmonic distortion, and resonances in the offshore grids have been reported because of harmonic interactions among active components such as power converters and passive components such as filters and grid impedance (Buchhagen et al., 2015; Kocewiak et al., 2013; Bradt et al., 2011). Furthermore, it is crucial to consider that the current limit recommendations in the standards do not apply to harmonic currents that are absorbed by WPPs from the background harmonic source of the grid. Therefore, series and parallel resonances from the capacitive collector cable can easily occur in the WPPs, by absorbing more harmonic current than determined in the standards (Kocewiak et al., 2017; Preciado et al., 2015). One of the promising study proposals for the harmonic stability of converter-based power systems is impedance-based analysis (Sun, 2011).

The harmonic content of the synchronous generator-based grids would contain low-order harmonics due to non-linear loads. Meanwhile a converter-based grid would mainly have high-order harmonics generated by high-frequency switching concepts of the power converters. Therefore, it is essential to emulate more realistic grid background harmonics using test equipment and evaluate the performance of the DUT with the presence of the grid harmonics. However, high-order harmonic injection would need high bandwidth in the output transformer of the AC grid emulator and the measurement instruments.

\subsection{Utility grid effects on a test bench}

The interconnection of the grid-emulating CGI and the utility grid depends on their characteristics. If the utility grid had low SCR, then the CGI connection to the utility grid would be very similar to an HVDC connection to a weak AC grid. According to Durrant et al. (2003), using current vector control for converters, only 0.4 per unit (pu) power transmission can be obtained for a DC link, where only in one of AC sides of the CGI (DUT or utility grid sides) is the SCR 1 pu. However, by using more efficient control methods or increasing DC-link capacitance, it can be increased to higher than $0.8 \mathrm{pu}$ (Zhang et al., 2011). Also, the connection of CGI to the utility grid should comply with the local grid connection requirements regarding power quality aspects. Therefore, it is vital to consider the local grid characteristics and connection requirements in design and control strategies for the test bench.

\section{Proposed test options for advanced test benches}

The proposed test structure for advanced test benches is illustrated in Fig. 4. Depending on the test modes and study objectives, the reference values for the controllers of the test bench converters would be prepared using either the powerhardware-in-the-loop (PHiL) interface or real-time system model simulations (Koralewicz et al., 2017; Averous et al., 2017). The electrical test options consist of two main groups including open-loop and closed-loop tests. The open-loop tests recreate the grid events according to predefined references and waveforms for the CGI converters for assessment 
of the DUT in WT and subsystem levels. The open-loop tests consist of IEC 61400-21-1 standard compliance tests and additional proposed tests including grid-following, gridforming, and black-start capabilities as well as harmonic stability tests. The second group of tests are proposed for validation of grid interactions at a system level including different grid connection topologies and characteristics. The closedloop tests would analyse the behaviour of the DUT in connection to a virtual WPP by online simulation of a detailed power system.

In addition, the blade and wind torque control unit for the wind torque emulator would be necessary in the case of WT's nacelle tests. Typically, the nacelle of the WT contains a gearbox, generator, converters, and output transformer. According to Fig. 4, the torque or speed references for the drive system can be derived from real-time calculations based on blade aerodynamics and mechanical models and wind speed time series. The control methods for converter-based CGI have been discussed in Gevorgian and Koralewicz (2016), Zeni et al. (2016), Espinoza and Carlson (2019), Espinoza et al. (2015), and Neshati et al. (2016). In the following sections the IEC 61400-21-1 standard tests and additional proposed open-loop tests as well as the proposed closed-loop tests are introduced for assessment of WTs and WPPs.

\subsection{IEC 61400-21-1 standard open-loop tests}

Today, most of the industrial test benches have been focused on performing the grid connection compliance tests, which are recommended in the IEC 61400-21 standard. In this section, the electrical characteristics to be simulated and validated for wind turbines are studied according to the IEC61400-21-1 standard (IEC 61400-21-1, 2019).

\subsubsection{Power quality aspects}

The power quality tests consist of measurement of harmonic emissions and flicker tests. Flicker addresses the voltage fluctuations imposed by WTs under continuous and switching operation conditions. Mainly, the flicker effect is considerable for the first generation of WTs without power converters, which were widely connected to distribution power systems in the previous millennium. The harmonic emission consists of current harmonics, inter-harmonics (noninteger multiples of the fundamental frequency), and higherfrequency components during continuous operation.

The power quality of the emulated AC grid can be arranged based on the emulated grid topologies, including HVDC or AC connection. The flicker can be generated by adding a low-frequency component to the fundamental frequency of reference signals for the AC grid emulator unit. In addition, to study the harmonic interactions of WTs in a WPP, the harmonic injection tests have been considered in several test sites (Gevorgian and Koralewicz, 2016; Sun et al., 2019). Depending on the converter switching frequency of the AC grid emulator, output filter, and transformers' bandwidth, part of the low-order harmonics can be injected to the connection point of the DUT. To date, there is no dedicated standard or regulation for harmonic interaction studies.

\subsubsection{Steady-state operation test}

The steady-state operation test evaluates the active power $(P)$ production against wind speed, maximum power, and reactive power $(Q)$ capability of the DUT. These characteristics aim to validate the power-speed and $P-Q$ curves. The test procedure and necessary measurements have been recommended in IEC 61400-21-1 (2019).

\subsubsection{Control performance test}

Active and reactive power-related controls by WT can be divided into two major categories: WT level control and WPP level control. Control performance testing of each of these categories requires special technique. The methods discussed in IEC61400-21-1 are related to the WT level control. Therefore, the control performance refers to the ability of a WT in terms of active and reactive power control and grid frequency support. The assessment of power control performance is verified by set-point tracking speed and steady-state error of the control system. Furthermore, the grid frequency support includes the active power reduction as a function of the grid over-frequency conditions. Providing additional active power during under-frequency events is another grid frequency supporting feature, which should be evaluated through the relevant tests.

\subsubsection{Transient performance test}

The transient performance or fault-ride-through (FRT) capability consists of low-voltage ride-through (LVRT) and highvoltage ride-through (HVRT) capabilities. Within the last decade, several serious WT tripping incidents have been reported in different countries such as Germany, China, and the UK due to voltage dips (under-voltage) and swells (overvoltage). Voltage transients have led to cascaded system trips, over-voltage excursion in transmission systems, and serious frequency deviations in power grids (Langstadtler et al., 2015; Wiser et al., 2018; Zhang et al., 2016). In addition, the measurements on real WPPs have shown that during HVDC converter blocking, the voltage at the WT terminals may increase by $30 \%$ and can even spike up to 2.0 per unit (pu) by further transient processes (Erlich and Paz, 2016). These incidents have indicated the necessity of HVRT and LVRT capabilities for WTs. Consequently, by facing similar problems, some countries, such as Germany, Denmark, Spain, the USA, Italy, and Australia, have adapted the national network codes for both HVRT and LVRT capabilities. Accordingly, the FRT capability demands the WTs to tolerate a specified range of high- or low-voltage events for certain periods. 


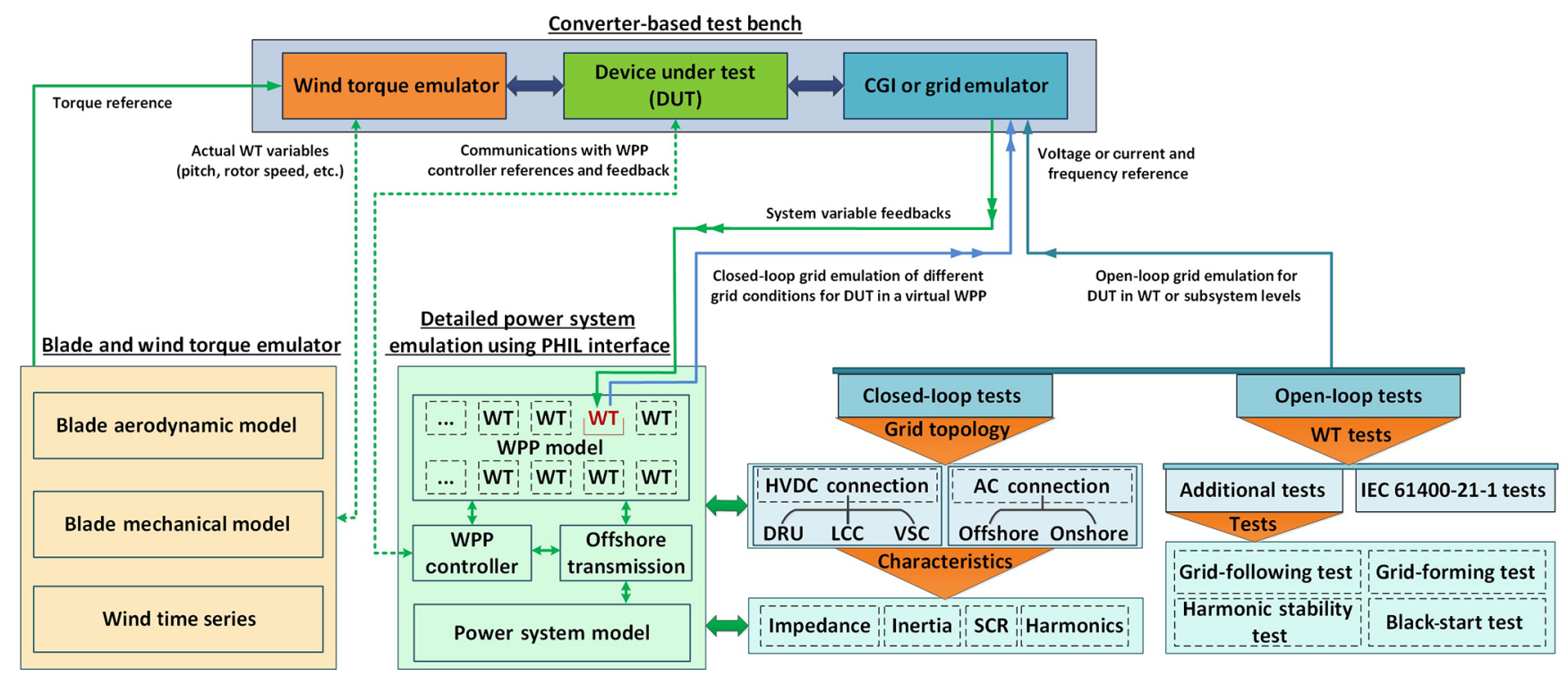

Figure 4. Proposed test structure for converter-based test benches.

The compliance tests can be implemented by giving openloop voltage reference values for the AC grid emulator as voltage-time profiles according to the network codes. However, in some test sites such as the one in Clemson University (Tuten et al., 2016), the LVRT test is performed using additional voltage divider equipment illustrated in Fig. 1. In the case of the LVRT capability test by converters, the active rectifier unit (ARU) would decrease the DC-link voltage to achieve an efficient modulation index and less voltage stress on switches and filters of the AC grid emulator. However, this is not possible in cases in which the wind torque emulator is connected directly to the ARU.

So far, the solutions for the HVRT capability test using full converters have been either utilization of step-up tap transformers or over-designing of the converters to be able to generate the required over-voltage range. In the case of converter over-design, the ARU should increase the DC-link voltage to make the over-voltage emulation possible for the $\mathrm{AC}$ grid emulator.

One of the critical specifications of a test setup for FRT tests is the rate of change of voltage (RoCoV) during the emulation of voltage dynamics for the DUT. The AC side converter should be able to simulate over-voltage or undervoltage events very fast. This is one of the main advantages of converter-based CGIs that can emulate $100 \%$ voltage changes within less than one cycle of the fundamental frequency of the grid. The fastness of a converter depends on ESCR, DC-link capacitors, short-circuit current capability of the AC grid emulator, control system, and overall system delays.

Furthermore, one of the recent studies in dynamic performance is the response of WTs against unbalanced faults. The unbalanced voltage deviations can be performed by setting positive and negative sequences in the voltage references and control loops for the AC grid emulator.

\subsubsection{Grid protection test}

Grid protection tests refer to the disconnection and reconnection functions of a grid-connected WT following its different protection schemes. Protection schemes for disconnection from the grid operate during extreme amplitude changes or the rate of changes in voltage and frequency of the grid. The relevant test procedure for the protection scheme evaluation is provided in IEC 61400-21-1 (2019).

\subsection{Additional proposed open-loop tests}

In this section, additional open-loop tests to the IEC 6140021-1 standard regarding WT capabilities are proposed, as presented in Fig. 4. The higher importance of the WT capability tests is because the system operators demand advanced capabilities from WPPs, and the wind turbine manufacturers are developing their products to achieve the grid connection requirements. Consequently, the new developments should be verified following appropriate test standards and regulations. Therefore, it is urgent to foresee the near future requirements in the standards. The grid connection compliance tests would be used for design validation of wind turbines or their subsystems as well.

\subsubsection{Harmonic stability test}

The harmonic stability issues and harmonic interactions, which are discussed in Sect. 4.1.4, can be studied by injecting harmonic voltages and currents into the terminals of the DUT using the test bench converters. This way, the 
harmonic model of WTs can be achieved or validated. The validated harmonic model of WTs, WPPs, and HVDC systems is necessary to perform harmonic stability analysis and eliminate possible interactions and resonances in design and development stages of WPPs. The experimental verification of the impedance-based stability analysis method for harmonic resonance phenomena is presented in Sun et al. (2019). Harmonic injection ability, using CGI converters or additional equipment, is another advantage of converterbased test sites (Averous et al., 2017; Gevorgian, 2018; Jersch, 2018; Rasmussen, 2015). Accordingly, converters' response to the specifically injected harmonics would help to analyse harmonic interactions with wind turbine control systems.

\subsubsection{Grid-forming capability test}

Recently, the grid protection ability of WTs has been extended to a new capability, called "grid-forming capability". WTs with grid-forming capability can perform as a voltage source to form a local AC network during disconnection from the main power grid and supply local loads. This capability is required, especially in the case of renewable-energybased grids in which the renewable energy systems should be able to support stability and power balancing of the grids. According to the grid connection requirements, WTs are allowed to disconnect from the AC grid during very severe voltage or frequency deviations out of their tolerable ranges. Meanwhile, grid-forming WTs can support local loads and increase the reliability of WPPs (Tijdink et al., 2017).

Test bench converters can simulate fault conditions for the DUT to evaluate the grid-forming capability of such WTs. During the grid-forming operation of the DUT, the CGI should perform as a current source converter and active load for the DUT. This study case would be more challenging when the WTs are meant to be used in an HVDC-connected offshore WPP in which there is no considerable local load for the offshore WPP. In all cases, the grid-forming capability is a temporary operation mode, which would be followed by reconnection to the grid and resuming the normal operation.

\subsubsection{System restoration and black-start capability test}

Following a partial or complete shutdown, it is crucial to restore the defected network and stabilize the overall power system. System restoration is the capability of reconnection of WTs to the grid after an incidental disconnection caused by a network disturbance. According to European network codes (Commission Regulation 631, 2016), the system restoration requirements consist of black-start, island operation, and quick re-synchronization capabilities. State-ofthe-art WTs can be equipped with functions such that they can start and run without the need for external auxiliary power supplies (Jain et al., 2018).
The black start would be essential for the start-up of a power generation unit or restart after shutting down due to faults. In a WPP, after the system shuts down, some WTs with black-start capability should be energized by an internal storage system. Then, the energized WTs should be able to energize the rest of the WTs by producing wind power over time (Tijdink et al., 2017; Jain et al., 2018). A similar process has been described for the black start of converters of an HVDC station (Commission Regulation 631, 2016). The performance of the DUT during system restoration conditions can be studied using advanced converter-based test benches.

\subsubsection{Grid-following capability test}

The electrical characteristics, which are considered in the IEC 61400-21-1 standard, only concern the performance of the DUT in grid-following mode. Therefore, the gridfollowing capability of the DUT addresses the control performance test, which is done for the nacelle of WTs in industrial test benches. By considering WTs with the capability of switching between grid-forming and grid-following operation modes, the grid-following capability test can be defined as part of different operation mode tests for advanced WTs. In addition, this test is applicable in WT and WPP levels using a PHiL interface as well.

\subsection{Proposed closed-loop tests}

In this section, the closed-loop tests are proposed concerning the grid integration challenges of WPPs, such as HVDC system interaction, weak grid conditions, sub-synchronicity, and interoperability of renewable energy systems. Different grid topologies and characteristics are considered in the proposed test options to emulate a more realistic grid connection for the DUT. It is evident that it is not feasible to simulate all different aspects of a real power system for a WT or WPP; however it is possible to assess part of the most critical conditions in a test environment and validate the simulation models (Ausin et al., 2008; Zeni et al., 2016).

\subsubsection{Detailed power system emulation}

The IEC 61400-21-1 standard considers the tests for a single WT, or its subsystems. However, these tests do not address the electrical power grid interconnection issues, such as converter interactions in a WPP level, grid characteristic influences, and power system stability issues. Detailed power system emulation can be performed through a power-hardwarein-the-loop (PHiL) interface. According to Fig. 4, the voltage, current, and frequency references for the CGI converters can be extracted from the overall system model, including WPP, transmission system, and power system models. 


\subsubsection{SCR and inertia emulation test}

SCR of the interconnected AC grid has an essential impact on the behaviour of WTs as discussed in Sect. 4.1.2. Emulation of a variable SCR and X/R ratio allows the study of the control system and stability of WTs. The number of converter modules and DC-link capacitors modifies the rating power and ESCR of the AC grid emulator. In addition, the software options for variable ESCRs are considering a virtual impedance and current and power limits in the control loops of converters. In Wang et al. (2015), the virtual impedance control method for a converter has been studied in detail.

The magnitude of feasible inertial response by WT generator and related stability implications would be highly dependent on the location of the WPP in the power grid and SCR of PCC, as mentioned in Sect. 4.1.3. The grid emulator would allow exploration of these limits using the RTDS system and relevant control schemes for the CGI converters. Therefore, it is possible to emulate all inertia ranges from the conventional generation $\left(H_{\mathrm{dc}}=14 \mathrm{~s}\right)$ down to HVDC-connected offshore grids $\left(H_{\mathrm{dc}}=0 \mathrm{~s}\right)$ in a test environment to assess the performance of WTs. In Zhu and Booth (2013), the inertia emulation control method using converters of an HVDC system is proposed. It is shown that the inertia of a voltage source converter depends on the number of capacitors, DC-link voltage, and output frequency. Therefore, these options can be used for inertia emulation by a CGI.

\subsubsection{Different grid connection test}

AC and HVDC transmission systems impose different electrical characteristics and control schemes on WPPs, as described in Sect. 2. The converter-based CGIs allow emulation of these differences for DUTs. The control and operation system of an HVDC system depend on the structure of the HVDC converters as well. Typically, there are three topologies for the HVDC converters illustrated in Fig. 4b: line commutated converters (LCCs), voltage source converters (VSCs), and diode rectifier units (DRUs) (Göksu et al., 2017). The CGI converters contain IGBT or IGCT switches in reversed-parallel connection with diodes. The converter switching method can be adjusted to perform switching based on the type of emulated HVDC topology.

The DRU-HVDC system is a cost-effective option to be used in offshore wind power transmission. To replicate a DRU-HVDC, all of the test-side converter switches should be turned off, and the remaining diodes can operate as a DRU converter. On the other hand, the ARU unit of the test bench should regulate the DC-link voltage. The control methods for DRU-HVDC connected offshore WPPs have been studied in Göksu et al. (2017).

\subsection{Discussion}

The test structure for converter-based test equipment is proposed and studied in two main groups, including open-loop and closed-loop tests. As discussed in Sect. 5, the state-ofthe-art test benches are adjustable to perform tests regarding the new capabilities of WTs, mainly by new control schemes for the converters of the test bench. In addition, the use of RTDS systems for online simulations and high-speed communications in the test bench would make it feasible to implement the closed-loop tests. This way, the increasing challenges regarding operation and control of WPPs can be simulated in a test environment. Furthermore, some parts of the tests, such as harmonic stability, transient performance, power quality, and control performance, would be useful for the design validation of WT and its subsystems as well. On the other hand, both groups of tests would be helpful to validate simulation models in WPP as well as WT levels. The tests on the DUT can be performed as such that the results would be transferable for higher levels including WT and WPP levels.

Operation and stability of WPPs depend on the interoperability and capabilities of the individual WTs. Since gridforming and black-start capabilities have already been required by system operators and included in the manufacturer design considerations, these two new features would be the most important capabilities which need to be addressed in the test standards. In addition, the harmonic interactions among converters have been reported as an increasing challenge for renewable energy systems. Therefore, harmonic stability of WPPs and HVDC systems is another important topic that should be studied and included in the standards.

The future works would involve implementation of the proposed additional test options and measurement data analysis. The authors aim to propose and evaluate new test methods using available advanced test benches to increase their beneficial applications and reduce the necessity of field tests, which are difficult and costly.

\section{Conclusions}

In this paper, the generic topology of converter-based test benches has been proposed. According to the structure of available industrial test benches, there is a strong potential for general harmonized topology and methods for test and assessment of WTs and WPPs. Primarily, the focus of IEC standard tests had been on the compliance test of WT capabilities through predefined open-loop tests. The new features of modern WTs, especially grid-forming and blackstart capabilities as well as harmonic stability considerations, have been required by system operators and developed by manufacturers to support renewable-energy-dominated power grids. These new features necessitate new or reformed test standards in the near future. Therefore, the appropriate additional test options for newly developed capabilities are proposed. In addition, increasing challenges in wind energy integration, such as control interactions, and grid characteristic influences, have compromised the renewable-generation- 
based power grids. In this regard, the closed-loop test options for the grid interaction tests concerning different grid characteristics and topologies are proposed. The electrical characteristics of different grids consist of impedance, inertia, SCR, and background harmonics. In addition, the grid topologies include AC and HVDC transmission systems, as well as different HVDC converter types. By real-time simulation of a detailed power grid, the wind integration challenges can be emulated in WT and WPP levels.

Most of the available advanced test sites are developed based on full converters. Therefore, the characteristics of a real power system can be emulated by the grid emulator coupled with RTDS systems through a high-bandwidth PHiL interface. Although it is not feasible to simulate all different aspects of a real power system, it is possible to assess part of the most critical conditions in a test environment and validate the simulation models for WTs and WPPs. This way, the possibility of research, development, and demonstration studies on WTs and WPPs would increase.

Data availability. All data and materials associated with this article can be found in the references given.

Author contributions. BN developed the new ideas of the paper with intense supervision of PES. BN and PES contributed to writing the original draft. VG and ÖG gave helpful reviews and edited of the paper. All co-authors contributed to the generic test bench structure and plotting of the figures. BN prepared the manuscript with contributions and revisions from all co-authors.

Competing interests. The authors declare that they have no conflict of interest.

Special issue statement. This article is part of the special issue "Wind Energy Science Conference 2019". It is a result of the Wind Energy Science Conference 2019, Cork, Ireland, 17-20 June 2019.

Acknowledgements. This work has received funding from PROMOTioN project as part of the European Union's Horizon 2020 Research and Innovation programme under grant agreement no. 691714 .

Financial support. This research has been supported by the Horizon 2020 (PROMOTioN (grant no. 691714)).

Review statement. This paper was edited by Hannele Holttinen and reviewed by Björn Andresen, Torben Jersch, and Ola Carlson.

\section{References}

ABB: Medium voltage AC drive, available at: https://library.e.abb. com/public/d30de1862c34d04dc1257b0c00551f88/ACS_6000_ EN_RevD-3.pdf (last access: 29 April 2020), 2018.

Andresen, B., Sørensen, P. E., Kocewiak, L., Martin, F., Nielsen, F. B., Dreyer T., and Ntovolos, K.: IEC TC 88 Wind Power Generation Standards in Relation to Grid Connection Requirements, 18th Wind Integration Workshop, 16-18 October 2019, Dublin, Ireland, 2019.

Asmine, M. and Langlois, C.É.: Wind Power Plants Grid Code Compliance Tests - Hydro-Québec TransÉnergie Experience, IET Ren. Pow. Gener., 11, 202-209, https://doi.org/10.1049/ietrpg.2016.0252, 2017.

Ausin, J. C., Gevers, D. N., and Andresen, B.: Fault ride-through capability test unit for wind turbines, Wind Energy, 11, 3-12, https://doi.org/10.1002/we.255, 2008.

Averous, N. R., Stieneker, M., Kock, S., Andrei, C., Helmedag, A., Doncker, R. W D., Hameyer, K., Jacobs, G., and Monti, A.: Development of a 4 MW Full-Size Wind-Turbine Test Bench, Emer. and Selec. Top. in Pow. Elect., 5, 600-609, https://doi.org/10.1109/JESTPE.2017.2667399, 2017.

Beza, M. and Bongiorno, M.: Identification of Resonance Interactions in Offshore-Wind Farms Connected to The Main Grid by MMC-based HVDC System, Journal of Electrical Power and Energy Systems, 111, 101-113, https://doi.org/10.1016/j.ijepes.2019.04.004, 2019.

Bradt, M., Badrzadeh, B., Camm, E., Mueller, D., Schoene, J., Siebert, T., Smith, T., Starke, M., and Walling, R.: Harmonics and Resonance Issues in WPPs, in: Proc. IEEE Power Energy Soc. General Meeting, 24-28 July 2011, Detroit, USA, 2011.

Buchhagen, C., Rauscher, C., Menze, A., and Jung, J.: BorWin1 - First Experiences with Harmonic Interactions in Converter Dominated Grids, International ETG Congress, VDE VERLAG gmbh, 17-18 November 2015, Berlin, Germany, 2015.

Chernet, S., Mebtu, B., and Bongiorno, M.: Investigation of Subsynchronous Control Interaction in DFIG-based Wind Farms Connected to A Series Compensated Transmission Line, Electr. Power and Ener. Systems, 105, 765-774, https://doi.org/10.1016/j.ijepes.2018.09.005, 2019.

CIGRE Technical Brochure 766: Network modelling for harmonic studies, CIGRE JWG C4/B4.38, available at: https://e-cigre.org/ publication/766-network-modelling-for-harmonic-studies (last access: 29 April 2020), 2019.

Commission Regulation (EU) 2016/1447 of 26 August 2016: Establishing a network code on requirements for grid connection of high voltage direct current systems and direct current-connected power park modules, Legislation 241/1, available at: https: //eur-lex.europa.eu/eli/reg/2016/1447/oj (last access: 29 April 2020), 2016.

Commission Regulation (EU) 2016/631 of 14 April 2016: Establishing a network code on requirements for grid connection of generators, Legislation 112/1, available at: https: //eur-lex.europa.eu/legal-content/EN/TXT/PDF/?uri=CELEX: 32016R0631\&from=EN (last access: 29 April 2020), 2016.

Cutululis, N. A.: MEDOW - Multi-terminal DC Grid for Offshore Wind, Final report, DTU Wind Energy E, No. 317221, Denmark, available at: https://backend.orbit.dtu.dk/ws/portalfiles/portal/ 
146792252/MEDOW_Final_Report_April2018.pdf (last access: 29 April 2020), 2018.

DNVGL-ST-0076: Design of electrical installations for wind turbines, Edition May 2015, available at: https://rules.dnvgl.com/ docs/pdf/DNVGL/ST/2015-05/DNVGL-ST-0076.pdf (last access: 29 April 2020), 2015.

Durrant, M., Werner, H., and Abbott, K.: Model of A VSC HVDC Terminal Attached to A Weak System, IEEE Conference on Control Applications, 25-25 June 2003, Istanbul, Turkey, 2003.

Erlich, I. and Paz, B.: Overvoltage Phenomena in Offshore Wind Farms Following Blocking of the HVDC Converters, IEEE Power and Energy Society General Meet. (PESGM), 17-21 July 2016, Boston, USA, 2016.

Espinoza, N. and Carlson, O.: Field-test of wind turbine by voltage source converter, Wind Energ. Sci., 4, 465-477, https://doi.org/10.5194/wes-4-465-2019, 2019.

Espinoza, N., Bongiorno, M., and Carlson, O.: Novel LVRT Testing Method for Wind Turbines Using Flexible VSC Technology, IEEE Trans. on Sust. Ener., 6, 1140-1149, https://doi.org/10.1109/TSTE.2015.2427392, 2015.

Fan, L. and Miao, Z.: An Explanation of Oscillations Due to Wind Power Plants Weak Grid Interconnection, IEEE Trans. on Sust. Ener., 9, 488-490, https://doi.org/10.1109/TSTE.2017.2713980, 2018.

GE: GE's Power Conversion, available at: https://www. gepowerconversion.com (last access: 29 April 2020), 2018.

Gevorgian, V.: NREL Controllable Grid Interface (CGI): Overview of Progress and Projects, 5th Annual International Workshop on Grid Simulator Testing of Energy Systems and WT Powertrains, 15-16 November 2018, Tallahassee, FL, USA, 2018.

Gevorgian, V. and Koralewicz, P.: Controllable Grid Interface for Testing Ancillary Service Controls and Fault Performance of Utility-Scale Wind Power Generation, 15th Wind Integration Workshop, 15-17 November 2016, Vienna, Austria, 2016.

Göksu, Ö., Cutululis, N. A., Altin, M., Saborío-Romano, O., Blasco-Gimenez, R., Bernal-Perez, S., AñóVillalba, S., Martinez-Turégano, J., Chaques-Herraiz, G., Perez, C., Motz, R., Purellku, I., Zeni, L., Kocewiak, Ł. H., Xu, L., Li, R., Finney, S., El-Khatib, W. Z., Abeyasekera, T., Brantl, C., Goldenbaum, N., Seman, S., Wuerflinger, K., Broy, A., Azpiri, I., Fadzeyeu, K., Abdalrahman, A., He, W., and Sharifabad, K.: Deliverable 3.2: Specifications of the control strategies and the simulation test cases, PROMOTioN, EU Project, available at: https://www. promotion-offshore.net/fileadmin/PDFs/D3.2_Specifications_ Control_strategies_and_simulation_test_cases.pdf (last access: 4 May 2020), 2017.

GWEC: Global statistics of global wind energy council, available at: http://gwec.net/global-figures/graphs/ (last access: 29 April 2020), 2018.

Hertem, D. V., Gomis-Bellmunt, O., and Liang, J.: HVDC GRIDs: For Offshore and Supergrid of the Future, Wiley-IEEE Press, ISBN 9781118859155, available at: https://www.wiley.com/en-dk/HVDC+Grids:+For+Offshore+ and+Supergrid+of+the+Future-p-9781118859155 (last access: 4 May 2020), 2016.

IEC 61400-21-1: 2019 - Wind energy generation systems - Part 21-1: Measurement and assessment of electrical characteristics - WTs, International Electrotechnical Commission, TC 88, ICS
28.180, available at: https://webstore.iec.ch/publication/29528 (last access: 4 May 2020), 2019.

IEC TR 61400-21-3: 2019 - Wind energy generation systems Part 21-3: Measurement and assessment of electrical characteristics - Wind turbine harmonic model and its application, International Electrotechnical Commission, TC 88, ICS 28.180, available at: https://webstore.iec.ch/publication/63755 (last access: 4 May 2020), 2019.

IEEE Std. 1094-1991: IEEE Recommended Practice for the Electrical Design and Operation of Windfarm Generating Stations, IEEE Standard Association, available at: https://standards.ieee. org/standard/1094-1991.html (last access: 29 April 2020), 1991.

IEEE Standard 1204-1997: IEEE Guide for Planning DC Links Terminating at AC Locations Having Low Short-Circuit Capacities, available at: https://ieeexplore.ieee.org/servlet/opac?punumber= 5251 (last access: 29 April 2020), 1997.

IRENA: Nurturing offshore wind markets: Good practices for international standardisation, International Renewable Energy Agency, Abu Dhabi, United Arab Emirates, 2018.

Jain, A., Das, K., Göksu, Ö., and Cutululis, N. A.: Control Solutions for Blackstart Capability and Islanding Operation of Offshore Wind Power Plants, 17th Wind Integration Workshop, 1719 October 2018, Stockholm, Sweden, 2018.

Jersch T.: Wind Assuring Confidence Through Competence, 5th Annual International Workshop on Grid Simulator Testing of Energy Systems and WT Powertrains, 15-16 November 2018, Tallahassee, FL, USA, 2018.

Joseph, D. M., Haigh, P., and McCullagh, J.: Ensuring Grid Code Harmonic Comliance of Wind Farms, 11th Wind Integration Workshop, 13-15 November 2012, Lisbon, Portugal, 2012.

Kalair, A., Abas, N., and Khan, N.: Comparative study of HVAC and HVDC transmission systems, Renew. Sust. Energ. Rev., 59, 1653-1675, https://doi.org/10.1016/j.rser.2015.12.288, 2016.

Kocewiak,Ł. H., Chaudhary, S., and Hesselbæk, B.: Harmonic Mitigation Methods in Large OWPPs, in: Proceedings 12th Wind Integration Workshop, 22-24 October 2013, London, UK, Energynautics GmbH, Germany, 2013.

Kocewiak, Ł. H., Gustavsen, B., and Hołdyk, A.: Wind Power Plant Transmission System Modelling for Harmonic Propagation and Small-signal Stability Analysis, in: Proceedings The 16th Wind Integration Workshop, 25-27 October 2017, Berlin, Germany, Energynautics GmbH, Germany, 2017.

Koralewicz, P., Gevorgian, V., and Wallen, R.: Multi-MegawattScale PowerHardware-in-the-Loop Interface for Testing Ancillary Grid Services by Converter-Coupled Generation, 18th IEEE Workshop on Control and Model. for Po. Electronics (COMPEL), 9-12 July 2017, Stanford, USA, 2017.

Langstädtler, J., Brelie, S. D. B., Schellschmidt, M., Schrobsdorff, S., Scheffer, J., and Kahlen C.: Relevance of high voltage ridethrough capabilities and testing, CIRED, 23rd Conference on Electricity Distribution, 15-18 June 2015, Lyon, France, No. 1391, 2015.

MEGAVIND: Test and Demonstration Facilities for Wind Energy Needed to promote a Competitive Wind Industry in Denmark, available at: https://megavind.winddenmark.dk/ test-and-demonstration-facilities (last access: 29 April 2020), 2016.

NERC: Integration of Variable Generation Task Force: Summary and Recommendations of 12 
Tasks, available at: https://www.nerc.com/comm/ PC/IntegrationofVariableGenerationTaskForceI1/

IVGTFSummaryandRecommendationReport_Final.pdf (last access: 29 April 2020), 2015.

Neshati, M., Zuga, A., and Wenske, J.: Hardware-in-the-loop drive train control for realistic emulation of rotor torque in a fullscale wind turbine nacelle test rig, European Control Conference (ECC), IEEE, 29 June-1 July 2016, Aalborg, Denmark, 2016.

Nouri, B., Arasteh, A., Göksu, Ö, Sakamuri, J. N., and Sørensen, P. E.: Comparison of European Network Codes for AC and HVDCconnected Renewable Energy Sources, 18th Wind Integration Workshop, 16-18 October 2019, Dublin, Ireland, 2019.

Pierri, E., Binder, O., Hemdan, N. G. A., and Kurrat M.: Challenges and Opportunities for A European HVDC Grid, Renew. Sust. Energ. Rev., 70, 427-456, https://doi.org/10.1016/j.rser.2016.11.233, 2017.

Pietilaeinen, K.: Grid Simulator Trends, 5th International Workshop on Grid Simulator Test of Powertrains, 15-16 November 2018, Tallahassee, FL, USA, 2018.

Preciado, V., Madrigal, M., Muljadi, E., and Gevorgian, V.: Harmonics in a Wind Power Plant, IEEE Power and Energy Society General Meeting, 26-30 July 2015, Denver, USA, 2015.

Rasmussen, L. S.: LORC Nacelle Testing, 3th Annual Int. Workshop on Grid Simulator Test of Powertrains, 5-6 November 2015, Tallahassee, FL, USA, 2015.

Sørensen, P.: IEC 61400-27 Series- Electrical Simulation Models of Wind Generation Systems, 18th Wind Integration Workshop, 16-18 October 2019, Dublin, Ireland, 2019.

Sørensen, P. E., Cutululis, N. A., Lund, T., Hansen, A. D., Sorensen, T., Hjerrild, J., Donovan, M. H., Christensen, L., and Nielsen, H. K.:: Power Quality Issues on Wind Power Installations in Denmark, IEEE Po. Eng. Society Gen. Meeting, 24-28 June 2007, Tampa, USA, 2007.

Sørensen, P., Göksu, Ö., Blasco-Gimenez, R., Brantl, C., bKahlen, C., Riechert, U., Despouys, O., and Chaffey, G.: Deliverable 11.1: Harmonization catalogue, PROMOTioN, EU Project, available at: https://www.promotion-offshore.net/ fileadmin/PDFs/D11.1_Harmonization_Catalogue.pdf (last access: 29 April 2020), 2019.

Sowa, I., Domínguez-García, J. L., and Gomis-Bellmunt, O.: Impedance-based Analysis of Harmonic Resonances in HVDC Connected Offshore Wind power Plants, Elect. Pow. Sys. Res. 166, 61-72, https://doi.org/10.1016/j.epsr.2018.10.003, 2019.

Sun, J.: Impedance-Based Stability Criterion for GridConnected Inverters, IEEE T. Power Electr., 26, 3075-3078, https://doi.org/10.1109/TPEL.2011.2136439, 2011.

Sun, Y., Yang, Y., Ruffing, P., Quester, M., Bernal-Perez, S., Añó-Villalba, S., Blasco-Gimenez, R., and Dowlatabadi, M. K.: Deliverable 16.5. Implementation of an Analytical Method for Analysis of Harmonic Resonance Phenomena, PROMOTioN, EU Project, available at: https://www.promotion-offshore.net/fileadmin/PDFs/D16.

5_Implementation_of_an_analytical_method_for_analysis_of_ harmonic_resonance_phenomena_v2.pdf (last access: 4 May 2020), 2019.

Tijdink, A., Groot, N. D., Karaolanis, A. A., Croes, A., Koreman, K., Yang, Y., Jafar, M., Plet, C., Belda, N. A., Göksu, Ö., Cutululis, N. A., Altin, M., Saborío-Romano, O., Bidadfar, A., Josefsson, J., Johannesson, N., Fadzeyeu, K., Hertem, D. V.,
Leterme, W., Crowley, R., Luscan, B., Poullain, S., Bertinato, A., Curis, J., He, W., Schettler, F., Broy, A., Würflinger, K., Petino, C., Quester, M., Zeni, L., Verfuss, T., Henneaux, P., Nesterov, D., Akhmatov, V., El-Khatib, W. Z., and Margarone, M.: Deliverable 1.5: Quantification of requirements, PROMOTioN, EU Project, available at: https://www.promotion-offshore.net/fileadmin/ PDFs/D1.5_PROMOTioN_Deliverable_1.5_Quantification_of_ requirements.pdf (last access: 5 May 2020), 2017.

Tuten, J., Haque, I., and Rigas, N.: Clemson University Wind Turbine Drivetrain Test Facility, Technical Report, available at: https://www.osti.gov/servlets/purl/1324502 (last access: 4 May 2020), 2016.

Wang, X., Li, Y. W., Blaabjerg, F., and Loh, P. C.: VirtualImpedance-Based Control for Voltage-Source and CurrentSource Converters, IEEE T. Power Electr., 30, 7019-7037, https://doi.org/10.1109/TPEL.2014.2382565, 2015.

Wind Europe: Wind energy in Europe: Outlook to 2022, available at: http://greenagenda.gr/wp-content/uploads/2018/09/ Wind-energy-in-Europe-Outlook-to-2022.pdf (last access: 29 April 2020), 2018.

Wiser, R., Bolinger, M., Barbose, G, Darghouth, N., Hoen, B., Mills, A., Rand, J., Millstein, D., Jeong, S., and Oteri, F.: Wind Technologies Market Report, U.S. Department of Energy, available at: https:/www.energy.gov/sites/prod/files/2019/08/ f65/2018WindTechnologiesMarketReportFINAL.pdf (last access: 5 May 2020), 2018.

Yang, Y., Blaabjerg, F., and Zou, Z.: Benchmarking of Voltage Sag Generators, in: Proceedings of Annual IEEE Conference on Industrial Electronics Socity, 25-28 October 2012, Montreal, Canada, 943-948, 2012.

Yogarathinam, A., Kaur, J., and Chaudhuri, N. R.: Impact of Inertia and Effective Short Circuit Ratio on Control of Frequency in Weak Grids Interfacing LCC-HVDC and DFIGBased Wind Farms, IEEE T. Power Deliver., 32, 2040-2051, https://doi.org/10.1109/TPWRD.2016.2607205, 2017.

Zeni, L., Gevorgian V., Wallen, R., Bech, J., Sørensen, P. E., and Hesselbæk, B.: Utilisation of Real-scale Renewable Energy Test Facility for Validation of Generic Wind Turbine and Wind Power Plant Controller Models, IET Renew. Power Gen., 10, 11231131, https://doi.org/10.1049/iet-rpg.2015.0478, 2016.

Zhang, L., Harnefors, L., and Nee, H. P.: Interconnection of Two Very Weak AC Systems by VSC-HVDC Links Using PowerSynchronization Control, IEEE T. Power Syst., 26, 344-355, https://doi.org/10.1109/TPWRS.2010.2047875, 2011.

Zhang, Y., Tang, N., Niu, Y., and Du, X.: Wind Energy Rejection in China: Current Status, Reasons and Perspectives, J. Renew. Sustain. Ener., 66, 322-344, 2016.

Zhou, J. Z., Ding, H., Fan, S., Zhang, Y., and Gole, A. M.: Impact of Short-Circuit Ratio and Phase-LockedLoop Parameters on the Small-Signal Behavior of a VSCHVDC Converter, IEEE T. Power Deliver., 29, 2287-2296, https://doi.org/10.1109/TPWRD.2014.2330518, 2014.

Zhu, J. and Booth, C. D.: Inertia Emulation Control Strategy for VSC-HVDC Transmission System, IEEE T. Power Syst., 28, 1277-1287, https://doi.org/10.1109/TPWRS.2012.2213101, 2013. 